\title{
Somogy megye fürkészlegyeinek katalógusa (Diptera: Tachinidae)
}

\author{
TÓTH SÁNDOR
}

Tórh S.: Checklist of parasite flies of Somogy county (Diptera: Tachinidae)

Abstarct: The fauna list of Somogy county is based on the records of the faunistical researchprograms organized in this area [Barcsi Juniper woodland (MIHÁLYI \& TÓTH 1985), Boronka-melléki Landscape Protection Area (TÓTH 1992) and the Duna-Dráva National Park (Tóth 1995)]. According to these data and to an unpublished manuscript (TóTH in print) the parasite fly fauna of Somogy county comprises 174 species at present. This is $41 \%$ of the presently known Hungarian fauna. From the rare species recorded in the county, the following ones are worth mentioning Catharosia flavicomis (Zetterstedt, 1859), Dexiosoma canina (Fabricius, 1781), Gymnosoma rungsi (Mesnil, 1952), Thelaira leucozona (Panzer, 1809), Tlephusa cincinna (Rondani, 1859).

\section{Bevezetés}

A fürkészlegyek kivétel nélkül erôsen alkalmazkodott belsô paraziták, a legtöbb fajuk a lepkehernyókat fertózi meg, de vannak fürkészlégy parazitái a hártyásszárnyúaknak, bogaraknak, poloskáknak, kabócáknak stb. is. A leghasznosabb rovarok közé tartoznak. Rendkívül fontos szerepük van a rovarok, de különösen az erdészeti kártevők leküzdésében. Jelentôségüket bizonyítja, hogy miután a gyapjaspille (Lymantria dispar) nagymértékben elszaporodott az Egyesült Államokban, Európából, elsősorban Magyarországról telepítették be a természetes ellenségeit, többek között fürkészlegyeket, a kártevő megfékezésére.

A fürkészlegyek kutatásának ennek ellenére - leszámítva néhány kártevő (pl. gyapjaslepke, amerikai fehér szövőlepke) parazitáit - Magyarországon nem volt komolyabb hagyománya. A Magyar Birodalom Állatvilága (Fauna Regni Hungariae) monográfiában (THALHAMMER 1899) mindössze 3 faj adatát találhatjuk Somogy megyéböl: Cylindromyia pusilla (Meigen, 1824) = Ószöd (Balatonőszöd), Dexiosoma canina (Fabricius, 1781) = Barcs, Senometopia excisa (Fallén, 1820) = Barcs.

A Magyar Természettudományi Múzeum fürkészlégy gyưjteményét Mihályi Ferenc feldolgozta, de a faunisztikai adatokat nem közölte. A Magyarország Állatvilága sorozat fürkészlegyeket tárgyaló kötete (MrHÁLYI 1986) csak kivételesen említ Somogy megyéból lelóhelyet (pl. Atylostoma tricolor, Taranyból). Ezért Somogy megye faunalistájának összeállításához, elsősorban csak a megyében szervezett programok keretében gyújtött fürkészlégy adatok állnak rendelkezésre. Ilyen program volt a Barcsi Borókás (MiHÁLYI és TótH 1985), a Boronka-melléki Tájvédelmi Körzet (TótH 1992) és a Duna-Dráva Nemzeti Park (TóTH 1995) kutatása.

A Duna-Dráva Nemzeti Parkból, valamint Somogy megye egyéb részeiból (pl. Baláta, Zselic) származó kétszárnyú családok publikálatlan adataiból (be- 
leértve a fürkészlegyeket is) összeállított, jelenleg kéziratban lévő dolgozat (TóTH előkészületben) adatait is célszerú volt beépíteni a faunalistába. Ilyen formán összesen 174 faj alkotja Somogy megye jelenleg nyilvántartott fürkészlégy faunáját, ami elég jelentốs szám, mivel kereken 41\%-át teszi ki a 425 fajból álló ismert magyarországi faunának.

A megyéből számos ritkának tekinthetô fürkészlegyet ismerünk. Ilyenek pl.: Catharosia flavicornis (Zetterstedt, 1859), Dexiosoma canina (Fabricius, 1781), Gymnosoma rungsi (Mesnil, 1952), Thelaira leucozona (Panzer, 1809), Tlephusa cincinna (Rondani, 1859). További három faj azért emelhető ki, mert ezeket elsősorban hegyvidéki elemként tartjuk számon, így somogyi előfordulásuk állatföldrajzi szempontból is érdekes: Nowickia ferox (Panzer, 1809), Phasia hemiptera (Fabricius, 1794), Siphona flavifrons Staeger, 1849.

\section{A Somogyból ismert fajok jegyzéke}

Acemya acuticornis (Meigen, 1824) - Tóth 1995, Tóth (elókészületben)

Actia crassicornis (Meigen, 1824) - Mihályi Tóth 1985, Tóth 1992, 1995, Tóth (elókészületben)

Actia infantula (Zetterstedt, 1844) - Tóth 1992, 1995, Tóth (elókészületben). Ritkább, fóleg a hegyvidékeinkról ismert faj. 1995

Actia pilipennis (Fallén, 1810) - Tóth 1992,

Aphria longilingua Rondani, 1861 - Mihályi Tóth 1985, Tóth 1992, 1995, Tóth (elökészületben).

Aphria longirostris (Meigen, 1824) - Tóth 1992. Fóleg hegyvidéken éló ritka faj.

Aplomya confinis (Fallén, 1820) - Mihályi Tóth 1985, Tóth 1995, Tóth (elökészületben)

Athrycia curvinervis (Zetterstedt, 1844) Mihályi - Tóth 1985. Ritka, Magyarországon korábban csak hegyvidékról ismerték.

Athrycia trepida (Meigen, 1824) - Tóth 1992, 1995, Tóth (elökészületben)

Atylostoma tricolor (Mik, 1884) - Tóth 1995 , Tóth (elökészületben). Ritka, Mihályi (1986) Taranyból említi.

Bessa parallela (Meigen, 1824) - Tóth 1992, 1995, Tóth (elökészületben)

Bessa selecta (Meigen, 1824) - Tóth 1992

Besseria lateritia (Meigen, 1824) - Tóth 1995. Ritka, Magyarországról kevés lelóhelyét ismerjük.

Billaea irrorata (Meigen, 1826) - Tóth 1992. Ritka, csak néhány lelóhelyrôl van adata.

Billaea pectinata (Meigen, 1826) - Tóth 1992, 1995, Tóth (elókészületben)

Billaea triangulifera (Zetterstedt, 1844) -
Tóth 1992, 1995. Ritka.

Bithia spreta (Meigen, 1824) - Tóth (elôkészületben)

Blepharipa pratensis (Meigen, 1824) - Tóth 1992, 1995, Tóth (elôkészületben)

Blepharipa schineri (Mesnil, 1939) - Tóth 1995, Tóth (elökészületben)

Blondelia nigripes (Fallén, 1810) - Mihályi Tóth 1985, Tóth 1992, 1995, Tóth (elókészületben)

Carcelia bombylans (Robineau-Desvoidy, 1830) - Tóth 1995, Tóth (elôkészületben)

Carcelia falenaria (Rondani, 1859) - Tóth 1992, 1995

Carcelia lucorum (Meigen, 1824) - Tóth 1995, Tóth (elókészületben)

Catharosia flavicornis (Zetterstedt, 1859) Tóth 1995. Ritka, Magyarországon korábban csak Fótról ismertük az előfordulást.

Catharosia pygmaea (Fallén, 1815) - Tóth 1992, 1995, Tóth (előkészületben). Ritka.

Ceromya bicolor (Meigen, 1824) - Tóth 1992, 1995, Tóth (elökészületben). Ritka.

Ceromya dorsigera Herting, 1967 - Tóth 1992. Ritka, néhány hazai példánya homokvidékekrốl került elö.

Ceromia silacea (Meigen, 1824) - Mihályi Tóth 1985, Tóth 1995, Tóth (elôkészületben). Ritka.

Chetogena filipalpis Rondani, 1859 - Mihályi Tóth 1985, 1995, Tóth (elökészületben)

Chetogena obliquata (Fallén, 1810) - Mihályi Tóth 1985. Ritka, fóleg vizes élőhelyeken találták.

Chrysomopsis auratus (Fallén, 1820) - Tóth 1992, 1995, Tóth (elôkészületben) 


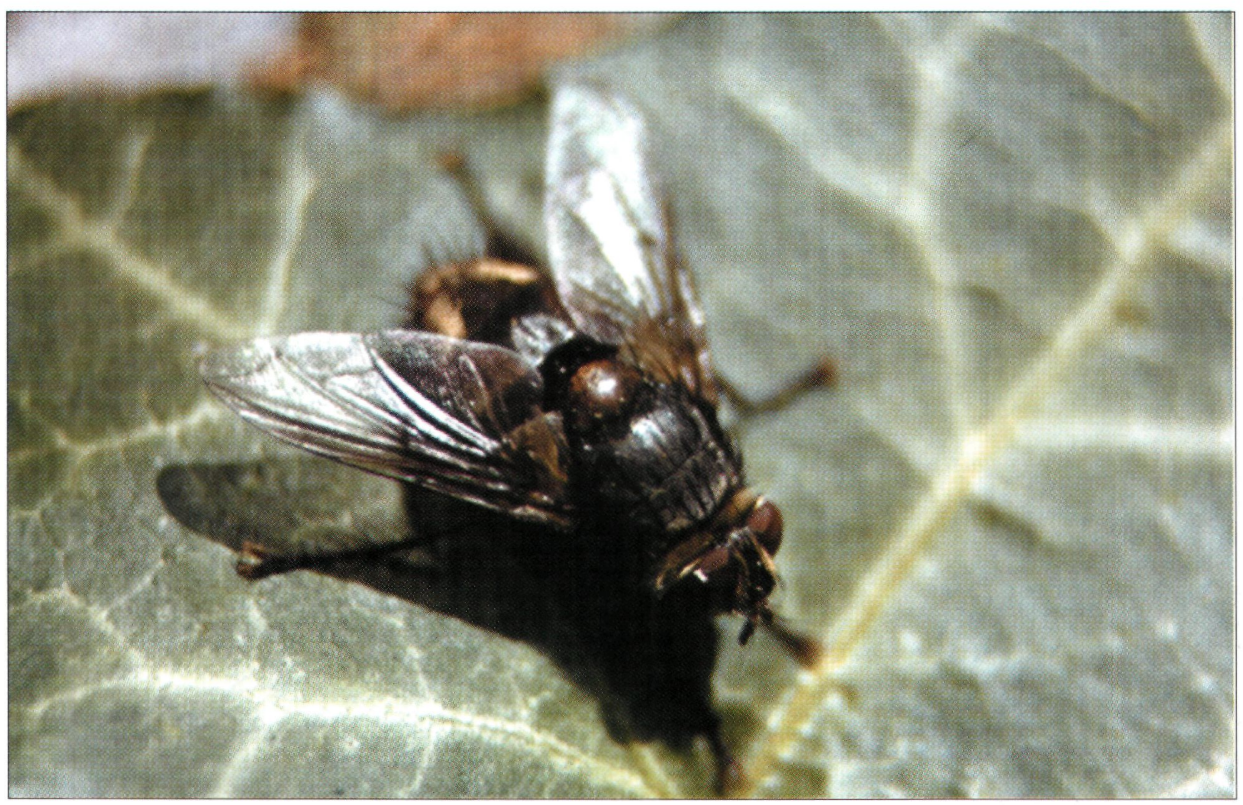

1. ábra: Gyapjapille bábfürkészlégy (Blepharipa pratensis) Fotó: Tóth S.

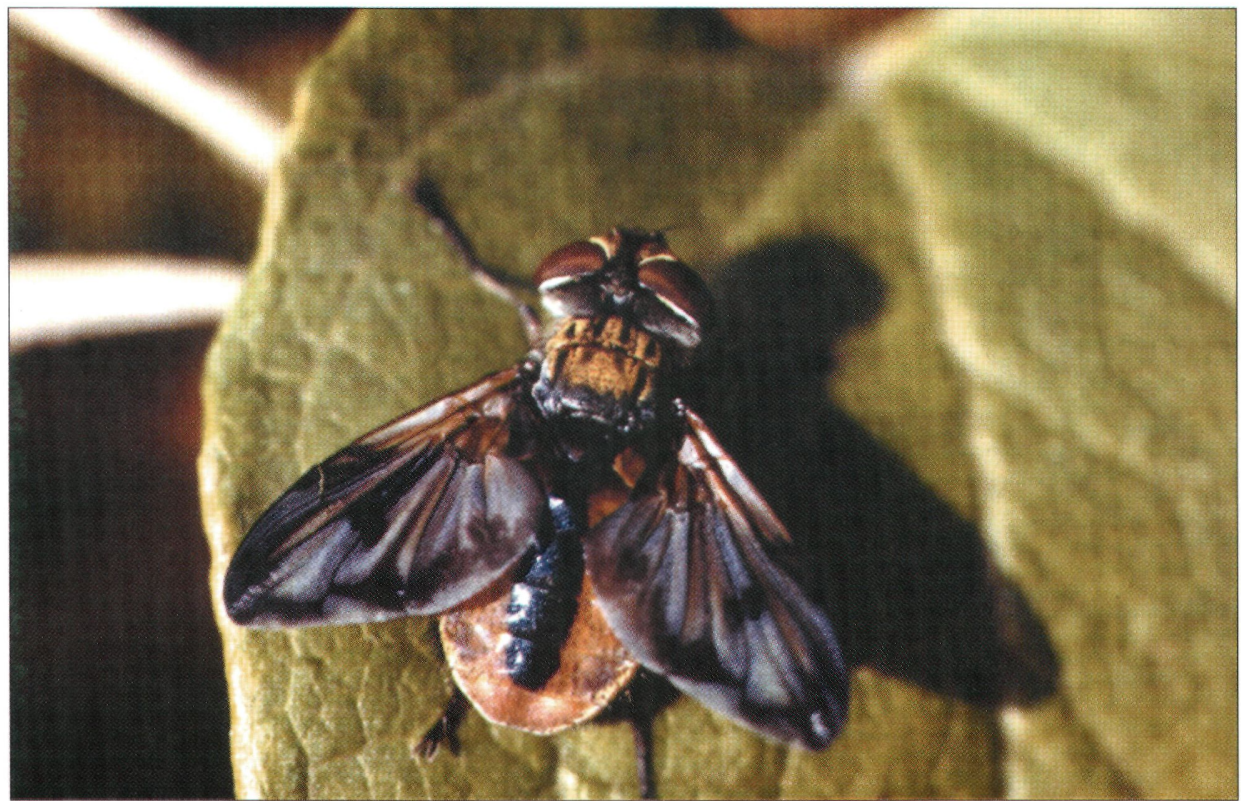

2. ábra: Szélespotrohú poloskafürkész (Ectophasia crassipennis) Fotó: Tóth S. 


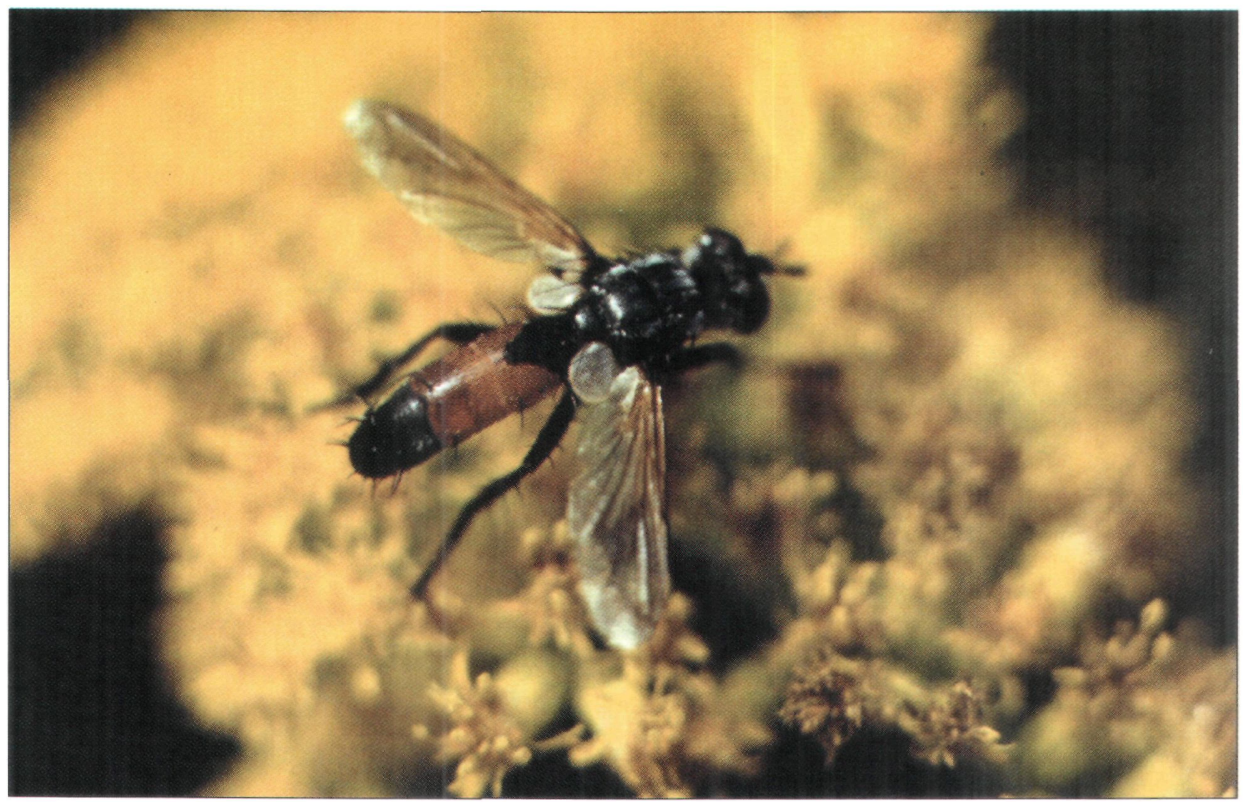

3. ábra: Karcsú poloskalégy (Cylindromyia brassicaria) Fotó: Tóth S.

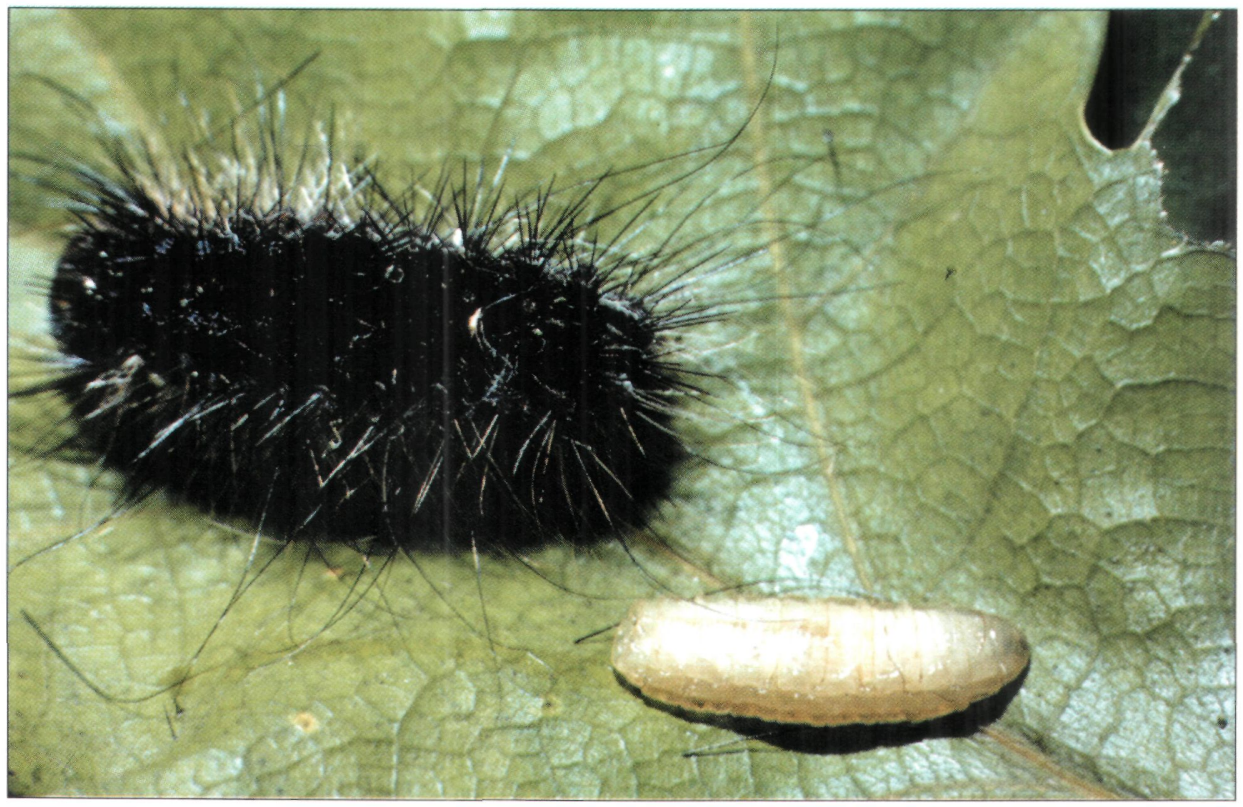

4. ábra: Gyapjaslepke fürkészlégy (Parasetigena silvestris) lárvája elpusztult gyapjaslepke hernyóval Fotó: Tóth S. 
Citogaster globosa (Fabricius, 1775) - Mihályi - Tóth 1985, Tóth 1992, 1995

Clemelis pullata (Meigen, 1824) - Tóth 1995

Clytiomya continua (Panzer, 1798) - Tóth 1992, 1995, Tóth (elókészületben)

Compsilura concinnata (Meigen, 1824) Tóth 1992, 1995

Cylindromyia auriceps (Meigen, 1838) - Mihályi - Tóth 1985, Tóth 1992, 1995, Tóth (elókészületben)

Cylindromyia bicolor (Olivier, 1812) - Tóth

1992, 1995, Tóth (előkészületben)

Cylindromyia brassicaria (Fabricius, 1775) -

Tóth 1992, 1995

Cylindromyia intermedia (Meigen, 1824 .

Tóth 1992, 1995

Cylindromyia interrupta (Meigen, 1824) -

Tóth 1992, 1995

Cylindromyia pilipes (Loew, 1844) - Mihályi Tóth 1985, Tóth 1992, 1995

Cylindromyia pusilla (Meigen, 1824) .

Thalhammer 1899, Tóth 1995

Cylindromyia xylotina (Egger, 1860) - Tóth

1995. Ritka, korábbi adatai hegyvidékekrôl származnak.

Cyzenis albicans (Fallén, 1810) - Tóth (elökészületben)

Dexia rustica (Fabricius, 1775) - Mihályi Tóth 1985, Tóth 1995, Tóth (elókészületben)

Dexiosoma canina (Fabricius, 1781) -

Thalhammer 1899 (Barcs). Ritka, Somogy megyében újabban nem sikerült gyújjteni, jelenlegi adatai a Bakony hegységból származnak.

Dinera carinifrons (Fallén, 1817) - Mihályi Tóth 1985, Tóth 1992, 1995

Drino vicina (Zetterstedt, 1849) - Mihályi Tóth 1985

Dufouria chalybeata (Meigen, 1824) - Tóth 1992, 1995, Tóth (elókészületben)

Ectophasia crassipennis (Fabricius, 1794) Mihályi - Tóth 1985, Tóth 1992, 1995

Ectophasia oblonga (Robineau-Desvoidy, 1830) - Tóth 1992, 1995

Eliozeta helluo (Fabricius, 1805) - Tóth 1992, 1995, Tóth (elókészületben)

Eliozeta pellucens (Fallén, 1820) - Tóth 1992, 1995. Ritka, korábbi adatai hegyvidékról származnak.

Elomyia lateralis (Meigen, 1824) - Tóth 1992, 1995

Epicampocera succincta (Meigen, 1824) - Mihályi - Tóth 1985, Tóth 1992, 1995

Eriothrix argyreatus (Meigen, 1824) - Tóth 1995, Tóth (elökészületben)
Eriothrix rufomaculatus (De Geer, 1776) Mihályi - Tóth 1985, Tóth 1992, 1995, Tóth (elókészületben)

Emestia rudis (Fallén, 1810) - Tóth 1992, 1995, Tóth (elókészületben)

Emestia puparum (Fabricius, 1794) - Tóth 1992, 1995. Ritka.

Erycia fatua (Meigen, 1824) - Mihályi Tóth 1985, Tóth 1995

Erycilla ferruginea (Meigen, 1824) - Mihályi Tóth 1985, Tóth 1992

Erythrocera nigripes (Robineau-Desvoidy, 1830 - Mihályi - Tóth 1985, Tóth 1995, Tóth (elókészületben)

Eumea linearicornis (Zetterstedt, 1844) Tóth 1992, 1995, Tóth (elókészületben) 1995

Eurithia caesia (Fallén, 1810) - Tóth 1992,

Exorista glossatorum (Rondani, 1859) - Tóth 1992. Ritka.

Exorista larvarum (Linnaeus, 1758) - Mihályi - Tóth 1985, Tóth 1995, Tóth (elókészületben)

Exorista rustica (Fallén, 1810) - Mihályi Tóth 1985, Tóth 1992, 1995

Frontina laeta (Meigen, 1824) - Mihályi Tóth 1985, Tóth 1992, Tóth (elókészületben)

Gonia capitata (De Geer, 1776) - Tóth 1992

Gonia divisa Meigen, 1826 - Tóth 1992, 1995, Tóth (elókészületben)

Gonia ornata Meigen, 1826 - Mihályi Tóth 1985, Tóth 1992, 1995, Tóth (elókészületben)

Gonia vacua Meigen, 1826 - Tóth 1992, 1995, Tóth (elókészületben)

Gymnochaeta viridis (Fallén, 1810) - Tóth 1995, Tóth (elókészületben)

Gymnosoma clavata (Rohdendorf, 1947)

- Mihályi - Tóth 1985, Tóth 1992, 1995, Tóth (elökészületben) 1995

Gymnosoma costata (Panzer, 1800) - Tóth

Gymnosoma dolycoridis Dupuis, 1961 - Mihályi - Tóth 1985, Tóth 1992, 1995 1995

Gymnosoma inomatum Zimin, 1966 - Tóth

Gymnosoma nitens Meigen, 1824 - Tóth 1995, Tóth (elókészületben)

Gymnosoma nudifrons Herting, 1966 - Mihályi - Tóth 1985, Tóth 1992, 1995, Tóth (elökészületben)

Gymnosoma rotundatum (Linnaeus, 1758) Mihályi - Tóth 1985, Tóth 1992, 1995

Gymnosoma rungsi (Mesnil, 1952) - Mihályi Tóth 1985. Ritka, a Barcsi Borókáson kívül a Kiskunságban gyújtötték. 
Hemyda obscuripennis (Meigen, I824) - Tóth 1992, 1995, Tóth (elókészületben). Ritka (Sopronból, Zemplén).

Hemyda vittata (Meigen, 1824) - Tóth 1995. Ritka, fóleg hegyvidéken találták. 1995

Leskia aurea (Fallén, 1820) - Tóth 1992,

Leucostoma anthracinum (Meigen, 1824) Tóth 1992

Leucostoma simplex (Fallén, 1815) - Tóth 1995, Tóth (elökészületben)

Linnaemya fissiglobula Pandellé, 1895 - Tóth 1992, 1995

Linnaemya frater (Rondani, 1859) - Mihályi Tóth 1985, Tóth 1992

Linnaemya impudica (Rondani, 1859) - Tóth 1992, 1995

Linnaemya media Zimin, 1954 - Mihályi Tóth 1985, Tóth I992, 1995, Tóth (elókészületben)

Linnaemya picta (Meigen, 1824) - Mihályi Tóth 1985, Tóth 1992, 1995

Linnaemya tessellans (Robineau-Desvoidy, 1830) - Mihályi - Tóth 1985, Tóth 1992

Linnaemya vulpina (Fallén, 1810) - Tóth 1992, 1995, Tóth (elökészületben)

Linnaemya zachwatkini Zimin, 1954 - Mihályi - Tóth 1985

Loewia phaeoptera (Meigen, I 824) -Tóth 1992, 1995, Tóth (elókészületben)

Lydella grisescens Robineau-Desvoidy, 1830 Tóth (elókészületben)

Lydella stabulans (Meigen, 1824) - Mihályi T'óth 1985, Tóth 1995, Tóth (elókészületben)

Lypha dubia (Fallén, 1810) - Tóth 1992

Macquartia tenebricosa (Meigen, I824) - Mihályi - Tóth 1985, Tóth 1992, 1995, Tóth (elốkészületben)

Masicera silvatica (Fallén, 1810) - Mihályi Tóth 1985, Tóth 1992, 1995, Tóth (elókészületben)

Medina luctuosa (Meigen, 1824) - Tóth 1992, 1995

Medina separata (Meigen, 1824) - Tóth 1992, 1995

Meigenia dorsalis (Meigen, 1824) - Tóth 1992, 1995, Tóth (elökészületben)

Meigenia incana (Fallén, 1810) - Tóth 1992

Meigenia mutabilis (Fallén, 1810) - Tóth 1992, 1995, Tóth (elókészületben)

Meigenia uncinata Mesnil, 1967 - Tóth 1992, 1995, Tóth (elökészületben)

Meriana puparum (Fabricius, 1794) - Tóth (clôkészületben)
Microphthalma europaea Egger, 1860 - Tóth 1992,1995

Microsoma exigua (Meigen, 1824) - Tóth 1992, 1995

Mintho rufiventris (Fallén, 1817) - Mihályi Tóth 1985, Tóth 1995, Tóth (elôkészületben)

Nemoraea pellucida (Meigen, 1824) - Mihályi - Tóth 1985, Tóth 1992, 1995

Nemorilla maculosa (Meigen, 1824) - Tóth 1995

Nilea hortulana (Meigen, 1824) - Mihályi Tóth 1985. Ritka, Mihályi (1986) Kaposvárról említi.

Nowickia ferox (Panzer, 1809) - Mihályi Tóth 1985, Tóth 1992. Hegyvidéki fajként tartják számon, ezért mind a Barcsi Borókásban, mind a Boronka-melléki Tájvédelmi Körzetben való gyưjtése érdekes adat.

Oswaldia muscaria (Fallén, 1810) - Tóth 1992

Pales parida (Meigen, 1824) - Mihályi Tóth 1985, Tóth 1992, 1995, Tóth (elökészületben)

Parasetigena silvestris (Robineau-Desvoidy, 1863) - Mihályi - Tóth 1985, Tóth 1995, Tóth (elókészületben)

Peleteria rubescens (Robineau-Desvoidy, 1830) - Mihályi - Tóth 1985, Tóth 1992, 1995

Peleteria varia (Fabricius, 1794) - Mihályi Tóth 1985, Tóth 1992, 1995, Tóth (elókészületben)

Peribaea tibialis (Robineau-Desvoidy, 1851) Mihályi - Tóth 1985, Tóth 1992, 1995

Pericheta unicolor (Fallén, 1820) - Tóth 1992. Ritka, fôleg dunántúli lelóhelyeit ismerjük.

Periscepsia carbonaria (Panzer, [1798]) Tóth 1992, 1995, Tóth (elókészületben)

Phania curvicauda (Fallén, 1820) - Tóth 1992, 1995

Phania funesta (Meigen, 1824) - Tóth 1992, 1995, Tóth (elókészületben)

Phania incrassata Pandellé, 1894 - Tóth 1992, 1995

Phania thoracica Meigen, 1824 - Tóth 1992, 1995

Phasia aurigera (Egger, 1860) - Tóth 1992 , 1995

Phasia barbifrons (Girschner, 1887) - Tóth 1992, 1995

Phasia hemiptera (Fabricius, 1794) - Tóth 1995. Hegyvidéki fajként tartják számon, ezért Somogy megyei elófordulása figyelemre méltó. 
Phasia obesa (Fabricius, 1798) - Mihályi Tóth 1985, Tóth 1992, 1995, Tóth (elókészületben)

Phasia oblonga (Robineau-Desvoidy, 1830) Tóth (elókészuiletben)

Phasia pusilla Meigen, 1824 - Mihályi Tóth 1985, Tóth 1992, 1995

Phasia subcoleoptrata (Linné, 1767) - Tóth 1995, Tóth (elókészületben)

Phebellia nigripalpis (Robineau-Desvoidy, 1847) - Tóth 1995

Phorocera obscura (Fallén, 1810) - Tóth 1992,1995 1995

Phrino vetula (Meigen, 1824) - Tóth 1992,

Phryxe nemea (Meigen, 1824) - Mihályi Tóth 1985, Tóth 1992

Phryxe pulgaris (Fallén, 1810) - Mihályi Tóth 1985, Tóth 1992, 1995, 'Tóth (clókészületben)

Phyllomyia nolvulus (Fabricius, 1794) - Tóth 1992, 1995, Tóth (clókészületben)

Prosena siberita (Fabricius, 1775) - Mihályi Tóth 1985

Pseudogonia parisiaca (Robineau-Desvoidy, 1851) - Tóth 1992, 1995

Ramonda prunaria (Rondani, 186l) - Tóth 1992, 1995, Tóth (elókészületben) 1995

Rondania fasciata (Macquart, 1834) - Tóth

Senometopia excisa (Fallén, 1820). Thalhammer 1899 (Barcs). Nem gyakori, fóleg a síkságokon gyúítötték

Siphona cristata (Fabricius, 1805) - Tóth 1992, 1995, Tóth (előkészületben)

Siphona flavifrons Staeger, 1849 - Tóth 1995. Ritka, Somogy megyén kívül, hegyvidékeken fogtak belóle néhány példányt.

Siphona geniculata (De Geer, 1776) - Tóth 1992, 1995, Tóth (elókészületben)

Siphona hungarica Andersen, 1984 - Tóth 1992, 1995, Tơth (elókészületben)

Siphona maculata Staeger in Zetterstedt, 1849 - Tóth 1992, 1995, Tóth (elókészületben)

Siphona pauciseta Rondani, 1865 - Tóth 1992, 1995

Smidtia conspersa (Meigen, 1824) - Tóth 1992, 1995

Solieria fenestrata (Meigen, 1824) - Tóth 1992, 1995, Tóth (elókészületben)

Solieria pacifica (Meigen, 1824) - Tóth 1995, Tóth (elókészületben)
Solieria racua (Rondani, 1861) - Tóth 1995.

Ritka, kevés helyen gyújiötték.

Spallanzania hebes (Fallén, 1820) - Mihályi -

Tóth 1985, Tóth 1992, 1995, Tóth (elókészületben)

Spallanzania quadrimaculata Herting, 1967 Mihályi - Tóth 1985, Tóth 199.

Sturmia bella (Meigen, 1824) - Mihályi Tóth 1985, Tóth 1995, Tóth (elókészületben)

Tachina fera (Linnaeus, 1761) - Mihályi Tóth 1985, Tóth 1992, 1995, Tóth (elókészületben)

Tachina grossa (Linnaeus, 1758) - Tóth 1992, 1995, Tóth (elókészületben). Ritka, kevés helyen gyưijtötték.

Tachina lurida (Fabricius, 1781) - Tóth 1992, 1995

Tachina magnicornis (Zetterstedt, 1844) Mihályi - Tóth 1985, Tóth 1992, 1995, Tóth (elókészületben)

Tachina nupta (Rondani, 1859) - Mihályi Tóth 1985, Tóth 1992, 1995, Tóth (elókészületben)

Tachina praeceps Meigen, 1824 - Tóth 1992

Tachina ursina Meigen, 1824 - Tóth 1992, 1995, Tóth (elökészületben)

Thelaira leucozona (Panzer, 1809) - Tóth 1995. Ritka, Mihályi (1986) csak Tardról (Déli-Bükk) említi az elófordulását.

Thelaira nigripes (Fabricius, 1794) - Mihályi Tóth 1985, Tóth 1992, 1995, Tóth (elókészületben)

Tlephusa cincinna (Rondani, 1859) - Mihályi Tóth 1985. Ritka, Mihályi (1986) csak a Bakonyból (Eplény) említi.

Voria ruralis (Fallén, 1810) - Mihályi - Tóth 1985, Tóth 1992, 1995, Tóth (elókészületben) 1992

Wagneria cunctans (Meigen, 1824) - Tóth

Winthemia cruentata (Rondani, 1859) Tóth 1992

Winthemia quadripustulata (Fabricius, 1794) Mihályi - Tóth 1985, Tóth 1995

Zaira cinerea (Fallén, 1810) - Tóth 1995, Tóth (elökészületben)

Zenillia libatrix (Panzer, 1798) - Tóth 1995, Tóth (elókészületben)

Zeuxia cinerea Meigen, 1826 - Tóth (elókészületben)

Zophomyia temula (Scopoli, 1763) - Tóth 1992, 1995 


\title{
Irodalom
}

MiHÁLYI - TóTH 1985: A Barcsi Borókás fürkészlégy faunája (Diptera: Tachinidae) - Dunántúli Dolg. Term. tud. Sorozat 5: 163-169.

Thalhammer J., 1899: Ordo. Diptera. - In: A Magyar Birodalom Állatvilága (Fauna Regni Hungariae). p. 76.

Tớth S. 1992: A Boronka-melléki Tájvédelmi Körzet fürkészlégy faunája (Diptera: Tachinidae) Dunántúli Dolg. Term. tud. Sorozat 7: 315-329.

Tórt S. 1995: Adatok a Dráva mente kétszárnyú (Diptera) faunájához - Dunántúli Dolg. Term. tud. Sorozat 8: 161-172.

TớlH S. Adatok Somogy megye kétszárnyú (Diptera) faunájához - Somogy Megy. Múz. Közlem., (elókészületben)

\section{Checklist of parasite flies of Somogy county (Diptera: Tachinidae)}

\section{SÁNDOR TÓTH}

Although the parasite fly is one of the most useful species of insects, scientists in Hungary have never really focused their attention on this special species. In the monograph, Fauna Regni Hungariae (The Fauna of the Hungarian Empire, THALHAMMER, 1899) only the data of three species are mentioned: Cylindromyia pusilla (Meigen, 1824) = Ószöd (Balatonószöd), Dexiosoma canina (Fabricius, 1781) = Barcs, Senometopia excisa (Fallén, 1820) = Barcs.

The fauna list of Somogy county was based on the available data on parasite flies collected during the programs organized in the area, for example, during the survey of Barcsi Juniper woodland (MiHÁLYI \& TóTH, 1985), Boronkamelléki Landscape Protection Area (TóTH 1992) and the Duna-Dráva National Park (TóTH 1995). As an additional source, a manuscript (TóTH in print) containing unpublished data on the Duna-Dráva National Park and other parts of Somogy county (eg. Baláta, Zselic) was also used. According to these works, the parasite fly fauna of Somogy county consists of 174 species. This is a rather high number, equivalent to $41 \%$ of the Hungarian fauna comprising 425 species.

From the rare species recorded in the county the following ones can be mentioned: Catharosia flavicornis (Zetterstedt, 1859), Dexiosoma canina (Fabricius, 1781), Gymnosoma rungsi (Mesnil, 1952), Thelaira leucozona (Panzer, 1809), Tlephusa cincinna (Rondani, 1859). Futher three species are mentioned as montaneous faunistical elements: Nowickia ferox (Panzer, 1809), Phasia hemiptera (Fabricius, 1794), Siphona flavifrons Staeger, 1849.

\author{
Author's address: \\ Dr. Sándor TótH \\ $\mathrm{H}-8420$ Zirc \\ Széchenyi u. 2. \\ HUNGARY
}

